For the membership committee

One year, A. L. Melander, Pullman, Wash.

Two years, E. G. Titus, Logan, Utah.

Three years, H. J. Quayle, Riverside, Cal.

(Signed) E. G. Tiтus,

H. S. Sмiтн.

This report was duly accepted by the members and the officers as nominated were declared elected.

Chairman H. J. Quayle: Is there any other business to come before the house at this time?

DR. E. G. TITus: I wish to offer the following resolution:

Resolved, That we appreciate the use of the high school as a meeting place and express our sincere thanks to the City Board of Education for the use of the same.

This resolution was duly adopted by the house.

Champuian H. J. Quayle: We shall now take up the remainder of the papers. The first one this morning is by Mr. H. S. Smith.

\title{
AN ATTEMPT TO REDEFINE THE HOST RELATIONSHIPS EXHIBITED BY ENTOMOPHAGOUS INSECTS ${ }^{1}$
}

By HARRY Scott Smith, Superintendent California State Insectary, Sacramento, California

In any field of endeavor it is desirable occasionally to review the past, making such readjustments as may seem necessary in order to provide a more secure basis for future work. In zoölogy the taxonomist accomplishes this by monographing, as necessity may demand, the group in which he is interested. The monographer performs a valuable service, since he not only standardizes that which has been done by others before him, placing each known species in its proper phylogenetic position in the group, but he defines the species as well and, if his results be worthy, makes it unnecessary for future students to go back of his monograph. In this way much valuable time is saved, and many needless misunderstandings, through lack of proper definition, are avoided.

In biological work names are quite as necessary as in taxonomy, and a careful definition of a biological phenomenon is fully as important as a correct description of a genus. Just as descriptions of genera must occasionally be altered as new species are made known, just so must the terms in biology occasionally be altered to keep pace with the advance of knowledge in biology. Definitions in a growing science

1 Occasional contributions from the California State Insectary, No. 2. 
are things to be modified and limited, just as the science itself is modified and limited.

The use of entomophagous insects in economic entomology, while not exactly a new branch of science, has experienced a considerable development in recent years. This development has necessitated more careful biological work on entomophagous insects, and has indirectly resulted in the adoption of a number of new terms to designate, among other things, the many different types of host-relationships exhibited. Many of the terms having to do with insect parasitism have "just growed." They have never been defined, and as they originated at a time when our knowledge of the subject was much less than at present, we find that they frequently include, under one name, two or more distinct phenomena. In other cases two or more terms have been used to designate the same phenomenon. The host-rclationships of entomophagous insects is a subject of considerable complexity and an accurate definition of the different types is essential to a clear understanding of them. It has scemed to the writer that to redefine the old terms now in use, to standardize, in a way, the terminology of insect parasitism, would be to render a service to the workers in that branch of entomology. In the following pages will be found the writer's contribution, in so far as his limited knowledge of the subject will permit, to such a redefinition.

The term parasite itself is one of the most difficult to define and it will not be attempted here. In this paper, when the term parasite is used, it will be understood to refer to certain temporary entomophagous insects only, and not to those insects such as Mallophaga, etc., which depend upon animals other than Arthropods for their subsistence.

In recent years there have appeared two papers, ${ }^{1}$ by Messrs. Fiske and Pierce, in which certain phenomena connected with host-relations were defined. These will be referred to frequently later on.

\section{Parasitism and Predatism}

The first and simplest division usually made of entomophagous insects is based on their method of feeding. These divisions are usually designated as parasitic insects and predaceous insects, and these terms are generally used in what seems to be the correct sense. A parasitic insect, in the generally accepted sense, is one which passes its entire larval state within or upon a single individual host. A

${ }^{1}$ Fiske, W. F.: Superparasitism: An Important Factor in the Natural Control of Insects, Jour. Econ. ENT., vol. III, pp. 88-97; Pierce, W. D.: On 'Some Phases of Parasitism displayed by Insect Enemies of Weevils, Jour. Econ. EnT., vol. III, pp. 451-458. 
predaceous insect is one which requires more than a single individual of the host species for completing its development and this requirement would seem to necessitate a more or less well developed means of locomotion. There is, however, no definite division between parasitism and predatism and in certain cases it is difficult to know whether to call an insect a parasite or a predator. A case of this kind is the Ptcromalid scale-pdrasite Scutellista cyanea. If we follow the definition given above Scutellista might come in either the parasitic or predaceous category. The female Scutellista deposits her eggs beneath the adult black scale. The parasite larva, however, feeds upon the eggs of the host and requires a large number, frequently several hundred, to complete its development, although it always matures beneath and upon the eggs of a single host scale. The question then arises as to whether we should call Scutellista a parasite of the black scale or a predator upon black scale eggs. The definition of the term parasite might be enlarged to fit cases of this kind by saying that a parasite is an entomophagous insect which requires but a single individual host insect, or the eggs of a single individual, to complete its development. But in calling to mind the life-histories of various kinds of parasites we find that even this enlargement of the definition as generally understood will not serve to define the hostrelations in all cases. Macrorileyia ocanthi Ashm., a Chalcidoid parasite (?) of the trec-crickets, carries us a step farther. This socalled parasite lives in the pith of the twigs in which the tree-crickets have deposited their eggs and upon which it feeds. Unlike Scutellista, however, it may, and frequently does, feed upon the eggs of more than one indiridual tree-cricket, and by reason of this approaches still more closely to predatism. There are many examples of this type of hostrelations. In Italy there occur two Chalcidoid enemies of the alfalfa wecvil, one a Pteromalid and the other an Eupelmine, of similar habits. The eggs of the alfalfa weevil and other species of Phytonomus are deposited within the stems of the host-plant in clusters. The two parasites mentioned here feed upon these eggs not as egg-parasites but as predators, often devouring egg-masses from several different weevils. Excepting for the fact that one is protected and the other feeds in the open, there is no essential difference between these so-called parasites and the larva of Leucopis, for example, which feeds upon the eggs of mealy-bugs, or the larva of the Brown Lacewing, Hemerobius, which feeds upon the eggs of the same host. Scymnus, Hyperaspis and many other ladybirds have similar habits. In view of these facts, therefore, we can scarcely say that there is a definite line of demarcation between parasitism and predatism, but the two, like geographic races, intergrade, the two extremes being quite distinct. In fact there 
are some species of insects, like Aphelinus mytilaspidis, for example, which are both predaceous and parasitic, feeding either upon the adult insect, or the progeny beneath the parent insect. The distinction between parasitism and predatism is of no great importance, but it is well to bear in mind that many of the so-called parasites are parasites only because they belong to a parasitic group, and not by reason of their method of feeding.

The interrelations of the parasites themselves are quite complex and, it seems to the writer, not as yet well defined. A knowledge of these interrelations is of not a little importance when the subject of the control of noxious insects by their insect enemies is under consideration. There have been used in the past a number of phrases and terms to designate the different kinds or types of host-relations and of interrelations of the parasites themselves, many of them used in one sense by one author and in an entirely different sense by another. Obviously this is not conducive to a clear understanding of the subject and should if possible be avoided. Some of these terms and phrases are hyperparasitism, secondary parasitism, tertiary parasitism, superparasitism, accidental secondary parasitism, cannibal superparasitism, mixed superparasitism, true secondary parasitism, multiple parasitism, etc.

\section{HYPERPARASITISM}

The term hyperparasitism is generally used to denote any stage of parasitism other than primary. That is, either a secondary parasite or a tertiary parasite is a hyperparasite. This is a useful term in the entomological vocabulary and is generally confined to the above meaning, although some use it synonymously with "secondary." Misuse of the term occasionally occurs when, for example, parasites of ladybirds are called hyperparasites. There is certainly no valid excuse for calling a parasite of ladybirds a hyperparasite, since it is not a parasite of a parasite, but is simply a primary parasite of Coccinellidæ. The fact that ladybirds are usually beneficial should have no bearing in the case, and such use of the term is only confusing. Neither should primary parasites of any other predaceous insects such as Leucopis, Chrysopa, Syrphus, etc., be called hyperparasites, although we find such use of the term occasionally in entomological literature.

\section{INDIRECT PaRAsitism}

Indirect parasitism, which is a type of hyperparasitism, is most closely related to secondary parasitism, and has not heretofore been defined. This type of host-relationship can best be illustrated by examples. One of the most noteworthy instances of this type is the Chal- 
cidoid parasite Perilampus hyalinus, ${ }^{1}$ and is, so far as I know, the first case on record of an indirect parasite. Perilampus hyalinus has an hiatus in its known life-history, since we know nothing at the present time of its oviposition habits. But we do know that it attacks the larvæ of Hyphantria cunea, not for the purpose of breeding upon $\mathrm{Hy}-$ phantria, as it is unable to do this, but for the sake of the primary parasite which it harbors. Strangely enough, in the case of this particular parasite, it does not matter much what the primary parasite is, just so it is an intcrnal parasite of $H$. cunea. It will be seen then that in the type of host-relationship known as indirect parasitism there are always three insects necessarily concerned simultaneously if the indirect parasite is to succeed in reproducing: first, the host of the primary parasite; second, the primary parasite, and third, the indirect parasite. No other host conditions will suffice. It will readily be seen that this type of host-relationship represents a very different kind of parasitism from that occurring where a parasite oviposits directly into the primary and yet both have always been known as secondary parasitism. Types of host-relationship so widely different should be distinguished by different terms. I would restrict the term indirect parasitism to the type of symbiosis similar in a general way to that occurring in Perilampus hyalinus. As a definition of indirect parasitism I would suggest the following: Indirect parasitism is that type of symbiosis in which the one parasite attacks a host insect upon which it itself is incapable of breeding, for the sake of the primary parasite which it may harbor. Since the biology of so few parasitic insects is known it is impossible to say just to what extent indirect parasitism occurs in nature. Besides Perilampus hyalinus one or two other species of this genus are known to have this habit, although several species are known to be true primary parasites. In the Ichneumonoidea this type of parasitism is known to occur in Mesochorus pallipes, a parasite of the Braconid, A panteles fulvipes, which is in turn a parasite of the gypsy moth in Europe. Since several other species of this genus are parasitic on Apanteles species, it is probable that many of them have the same habit. To this class belong also a number of hyperparasites of scale insects. Among them are species of the genus Eusemion which are parasites of Microterys and Aphycus, in their turn parasites of the soft brown scale, species of Cheiloneurus which breed on various parasites of mealy-bugs and scales, and Cerchysius, a parasite in one case of Microterys on soft brown scale, and in another on Scutellista cyanea and Tomocera californica, parasites of the black scale.. ${ }^{2}$ Species

1 The Chalcidoid Genus Perilampus, and its Relations to the Problem of Parasite Introduction. Bul. 19, Tech. Ser., pt. IV, Bur. Ent., U.S.D.A.

2Vide Timberlake, "Parasites of Coccus hesperidum," Jour. Econ. ENT., vol. 6, pp. 293-303. 
of Figitidæ also have this habit, ovipositing into aphids in order to breed upon the aphidiines infesting them. Considered from an economic standpoint, these indirect parasites are of no greater importance, are capable of no greater harm, than are the other hyperparasites. In fact they are less to be feared as a general rule since their life-histories are more complex and the more complex an insect's life-history is, other things being equal, the less possibility there is of its becoming abundant.

\section{SeCondary Parasitism}

The type of host-relationship most closely allied to indirect parasitism, and most generally confused with it, is secondary parasitism. While these two forms of symbiosis bring about the same final result, $i . e$. , the destruction of the primary parasite, the manner of accomplishing this end is very different. Strictly speaking, a secondary parasite is merely a primary parasite of a primary parasite. While this is also true of the indirect parasite, they differ in that the adult of the indirect parasite does not oviposit directly in or upon its host, but into or upon the host of the primary. ${ }^{1}$ The adult of the secondary parasite deposits its eggs directly into or upon the body of the young primary.

The life-history of the true secondary is very simple as compared to the complex life-history of the indirect parasite. In the one case two insects only, the secondary and its host the primary, are concerned. In the other three insects, the indirect parasite, the primary parasite. and the host of the primary are all directly concerned.

True secondary parasitism is of very common occurrenco in nature, and is of great importance in the natural control of insects. Practically all species of primary hymenopterous parasites, and especially the cocoon-forming groups of which the Ichneumonoidea compose the majority, are greatly subject to attack by these insects. The Tachinidæ and other parasitic Diptera are also destroyed in large numbers. True secondary parasitism is of most common occurrence among the Chalcidoidea and is found especially in the families Eulophide and Pteromalidæ. It also occurs in the Eurytomidæ, Flasmidæ, Callimomidx and Chalcididx. It occurs very uncommonly, if at all, in the Encyrtidæ, since in that highly specialized family indirect parasitism takes the place of secondary parasitism. I do not call to mind at this time any case of secondary parasitism, as here defined, in the Proctotrypoidea or Cynipoidea, although in the lattcr indirect parasitism occasionally occurs. Secondary parasitism should occur in both of these superfamilies, however, since many species are parasites of Diptera and they will undoubtedly be found to attack some of the

${ }^{1}$ In the case of Perilampus hyalinus, the oviposition habits are unknown, but the young parasite larva or planidium is first found on the outside of the caterpillar. 
parasitic species. ${ }^{1}$ In the Ichneumonoidea secondary parasitism occasionally occurs, especially in the Cryptinæ.

As a definition I would suggest the following: Secondary parasitism is that type of symbiosis where a parasite destroys a primary parasite by direct attack, and not through the medium of the host of the primary parasite.

Since this type of insect has the same relation to primary parasites as the latter have to insect pests, it naturally follows that they are an extremely important consideration in the control of injurious inșects. They are in our native fauna responsible in many cases for the ineffective work of primary parasites which would otherwise be of great practical value. In the introduction of new beneficial insects it is obviously of greatest importance to guard against the introduction of these secondaries. Many primary parasites of little importance in their native habitat might, by introducing them into new localities, become of great practical value through the elimination of their secondaries, especially if these secondaries have no counterpart in the new locality. Occasionally, however, the newly introduced parasite is immediately attacked by secondaries native to the new locality and which had as their original host species of the same genus as the parasite introduced. A noteworthy instance of this kind occurred at the Gypsy Moth Parasite Laboratory of the U. S. Department of Agriculture. $^{2}$ Apanteles fulvipes, a common parasite of the gypsy moth in Europe and Japan, was introduced as a most promising species. In Europe it was found to be attacked by something like twenty-five species of secondaries and indirect parasites, and other hyperparasites. In Japan at least thirty species of hyperparasites occurred. During the first generation on American soil seventeen species of hyperparasites, for the most part different species but the same genera as those occurring in Europe and Japan, attacked Apanteles fulvipes.

In this case the elimination of the secondaries probably did not have a very important bearing on the success of the introduction, since the introduction of hyperparasites having the same habits as native parasites would merely serve to eliminate to a large degree the native hyperparasites, leaving the total percentage of mortality about the same as before. The introduction of secondaries which have no counterpart in the new fauna, however, would have an entirely different effect and the greatest care should be exercised to eliminate any hyperparasites which would form a new element in the local fauna. Obviously the only safe way of doing this is to eliminate them all.

1 Since writing the above I have come across a record of true secondary parasitism among the Proctotrypoidea by Mr. Swezey of the Sugar Planters' Station of Honolulu. A species of Ceraphron was found to parasitize II aplogonalopus, a Dryinid.

2 Howard and Fiske: Bul. 91, Bur. Ent., U.S.D.A. 


\section{Tertiary and Quaternary Parasitism}

Parasitism of a stage beyond that of secondary-if we disregard those cases of accidental or chance parasitism-is of not at all common occurrence. I do not at this moment recall a single authentic case of true quarternary parasitism, although such have been recorded. It will generally be found in the instances where parasites are recorded as quaternary that they are only accidentally so, the same species being by nature either secondary or tertiary. Some parasites such as Dibrachys boucheanus are so omnivorous in their food habits that they will develop on practically any parasite larvæ enclosed in a cocoon or puparium. This being the case, if they oviposit into a cocoon containing larvæ of a tertiary parasite they are able to develop on. the tertiary larvæ and then they become numerically speaking quaternary parasites. They are not, however, obligatory in this rôle, and if they are to be designated as quaternary at all the term should be modified by the word accidental. There are grave doubts as to whether an obligatory quaternary parasitic insect exists.

Obligatory tertiary parasitism does exist in nature and will no doubt be found to be a fairly common phenomenon when the life-histories of more parasitic insects are thoroughly known. The best instance of true tertiary parasitism is that of the Eulophid, Asecodes albitarsis. The writer has made hundreds of dissections of cocoons of various microgasterine parasites in New England and in every case Asecodes was found to be a true tertiary parasite, breeding generally upon Dibrachys boucheanus, a true secondary. Other species of the Entedonini will without doubt be found to belong to this category.

Dr. L. O. Howard in his interesting paper on the parasites of the Tussock moth, at the close of his chapter on the interrelations of the parasites, says: "We would naturally have expected a period of abundance of tertiary parasites to have followed that of the secondary parasites. This, however, was not the case. Tertiary parasitism seemed to be comparatively rare and was only definitely proven in the case of $A s$ ecodes albitarsis and Dibrachys boucheanus, the latter being usually a secondary parasite. . . . There must be a limit to this work of parasite upon parasite at some point and it seems certain that tertiary parasitism is rare and that quaternary parasitism seldom occurs."

As mentioned above, Dibrachys is in reality a secondary and becomes tertiary in this case only through accident and its omnivorous food habit. Asecodes is, however, an obligatory tertiary parasite. I would define then as tertiary parasitism that type of symbiosis where a parasite is obligatory upon an obligatory secondary. A true quaternary would necessarily be obligatory upon an obligatory tertiary parasite. I believe with Dr. Howard that there must be a limit 
to this work of parasite upon parasite and while it is perhaps unscientific to allow one's opinions to outstrip the facts, especially when so few life-histories of parasites are known, I doubt if true quaternary parasitism as defined above really exists among entomophagous insects. Accidental quaternary parasitism does of course occur in the case of omnivorous or general feeders such as Dibrachys or Melittobia and so far as this type of insects is concerned there is practically no limit to the numerical relations which may develop. Dibrachys will, for example, breed upon Asecodes and in its turn Asecodes will breed upon this generation of Dibrachys, and while this sort of thing can hardly go on ad infinitum as Burns would have us believe, it would certainly continue as long as the food supply lasts.

\section{Superparasitism and Multiple Parasitism}

Superparasitism has been defined by Fiske (loc. cit.) as that form of symbiosis resulting "when any individual host is attacked by two or more species of primary parasites or by one species more than once." We have under superparasitism as defined by Fiske two quite distinct phenomena. These were later designated by Pierce (loc. cit.) as cannibal superparasitism and mixed superparasitism. In a previous article Mr. Pierce gave to the latter phase of parasitism the term accidental secondary parasitism. This phase or rather these phases of parasitism have been so ably treated by the two entomologists mentioned, that there remains little to be said in this connection and those interested are referred to the two articles for further information. However, since the avowed purpose of this paper is to standardize the terminology of the host relations of entomophagous insects the subject cannot logically be left with two terms for the one phenomenon in one case and one term for two phenomena in the other.

The writer would suggest that the term superparasitism be restricted to those cases where there is a superabundance of parasites of a single species (cannibal superparasitism of Pierce). It frequently happens, especially when the total percentage of parasitism runs abnormally high, that the mother parasite deposits many more eggs than can possibly reach maturity on a single individual host, or in other cases, after one female parasite has laid her quota of eggs another female of the same species, lacking the ability to distinguish between parasitized and unparasitized hosts, deposits a further supply in the same individual. This phenomenon alone I would term superparasitism, leaving the other phase included in Fiske's superparasitism to be termed multiple parasitism (Pierce's accidental secondary parasitism and mixed superparasitism).

By way of definition I would suggest the following: Superparasitism 
is that form of symbiosis occurring when there is a superabundance of parasites of a single species attacking an individual host insect. Multiple parasitism is that form of symbiosis where the same individual host insect is infested simultaneously with the young of two or more different species of primary parasites. The term multiple parasitism has already been used by Pierce to designate gregarious parasites and while I dislike to use the same term for a different phenomenon I know of no unused expression which fits so well this phase of parasitism.

In a brief paper like this it is possible only to touch upon the main headings of the extensive subject of host-relationship of entomophagous insects. It has been attempted to define only the most important divisions, but each of those is of course divisible into a number of lesser types. While the writer is not so rash as to believe that there will be a general acceptance of these definitions by entomologists, he does hope that they will be of some assistance to students of this most interesting phase of biology.

Chatrman H. J. Quayle: The next paper will be on the dinpersion of scale insects by the wind.

\section{DISPERSION OF SCALE INSECTS BY THE WIND}

By H. J. QUAYLe, University of California, Citrus Experiment Station, Riverside, California

The manner and extent of dispersal of many insects have been largely conjectural until recent years, and even now exact data have been secured for comparatively few species. Of course, we have had records of the great distances that certain flying insects may travel. It is only necessary in this connection to mention such insects as the migratory locust, Schistocerca peregrina, which has been found five hundred miles east of its home in South America and is supposed to have crossed over even to Africa, or our own Rocky Mountain locust, which has gone one thousand miles from its breeding ground, or certain moths that have been seen over four hundred miles at sea.

It is only recently, lewever, that we have come into possession of definite data as to how far such f.yir g incecis as ti:e house-fly or such non-flying forms as gipsy moth larvæ may travel. Without authentic data, a few hundred feet or a few hundred yards was thought to be the limit of travel of the house-fly. The work of Arnold, Copeman, et al,

1 Paper No. 36, Citrus Experiment Station, College of Agriculture, University of California, Riverside, California. 